\title{
Atypical mycobacterial wound infection after blepharoplasty
}

\author{
Ramana S Moorthy, Narsing A Rao
}

Despite numetous reports of atypical mycobacterial infections,,$^{1-3}$ to our knowledge there have been no reports of atypical mycobacterial skin infections following oculoplastic procedures. We present a case of atypical mycobacterial wound infection after blepharoplasty.

Doheny Eye Institute, Los Angeles, USA R S Moorhty

N A Rao

Correspondence to: Narsing A Rao, MD, Doheny Eye Institute, 1355 San Pablo Street, Los Angeles, CA 90033, USA.

Accepted for publication 10 August 1994

Figure 1 Bilateral blepharoplasty wounds showing induration, breakdown, and crusting.
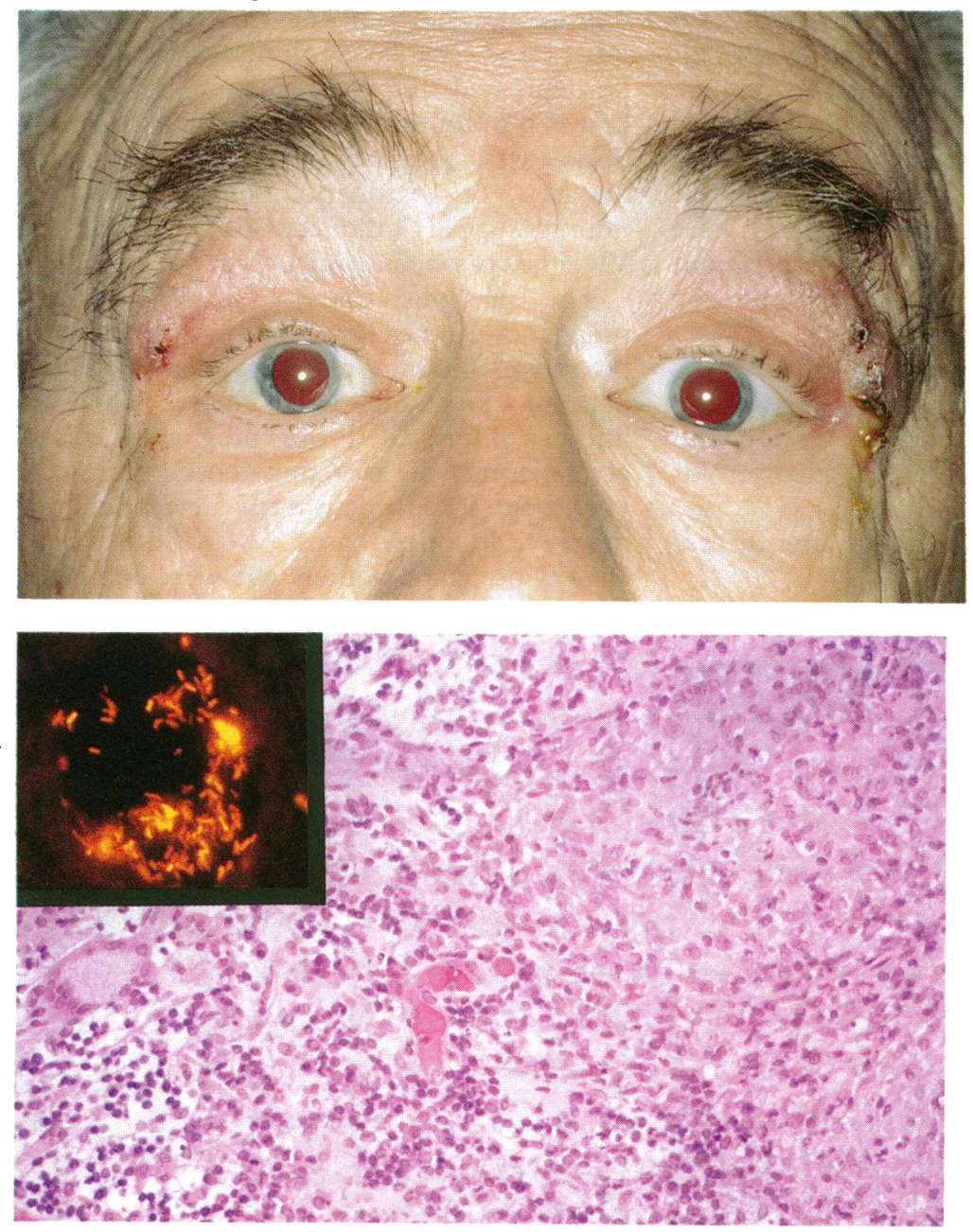

Figure 2 Light micrograph of debrided tissue showing infiltration of mononuclear cells, epithelioid cells, and an occasional giant cell (haematoxylin and eosin, magnification $\times 100$ ). Auramine-O stained section (inset) showing numerous rod-shaped bacteria (magnification $\times 240$ ). plasty for dermatochalasis. Four weeks later he noted increasing redness and swelling in the healed brow incisions. These swellings bled intermittently, scabbed over, and became progressively more prominent (Fig 1) despite treatment with cephalothin for 2 weeks. Because of the lack of response to this antibiotic, the patient was thought to have an atypical mycobacterial wound infection. Lowenstein-Jensen media were inoculated with the exudate of the wound and acid fast stains were obtained. The stain revealed several acid fast bacilli. There was growth on the media, which was identified as

\section{Case report}

A 72-year-old man underwent bilateral blepharo-

\section{Comment}

This case represents an unusual occurrence of ocular adnexal infection caused by Mycobacterium chelonae. The clinical features of atypical mycobacterial cutaneous infections include a history of trauma, failure of surgical wounds to heal or breakdown of previously healed wounds, serous drainage from infected wounds, and outbreaks of infections from the same institution. Several factors predispose patients to develop cutaneous and ocular disease from Mycobacterium chelonae. These include traumatic introduction of organisms into tissues, presence of foreign material, contaminated gentian violet marking solution, contaminated needles, and syrines, or injectables, and improper sterilisation of instruments. ${ }^{4}$ Strict sterile technique was employed during surgery in the present case; needles and suture material from the operating room were cultured, but no organisms were isolated.

Mycobacterium chelonae tends to be resistant to the usual antituberculous medications, including cycloserine, but clarithromycin may be helpful in fighting infections caused by this organism..$^{5}$ In addition to antibiotic therapy, debridement of the infected tissues is integral to the therapy of cutaneous atypical mycobacterial infections.

1 Smiddy WE, Miller D, Flynn HW Jr. Scleral buckle infections due to atypical mycobacteria. Retina 1991; 11: 394-8.

2 Dugel PU, Holland GN, Brown HH, Pettit TH, Hofbauer JD, Simons KB, et al. Mycobacterium fortuitum keratitis. Am $\mathscr{f}$ Ophthalmol 1988; 105: 661-9.

3 Smith RE, Salz JJ, Moors R, Silverstein D, Lewis W. Mycobacterium chelonae orbital granuloma after tear duct probing. Am f Ophthalmol 1980; 89: 139-41.

4 Safranek TJ, Jarvis WR, Carson LA, Cusick LB, Bland LA Swenson JM, et al. Mycobacterium chelonae wound infections after plastic surgery employing contaminated gentian tions after plastic surgery employing contaminated gentian
violet skin-marking solution. $N$ Engl f Med 1987; 317: 117violet 201.

5 Brown BA, Wallace RJ Jr, Onyi GO, De Rosas V, Wallace RJ III. Activities of four macrolides, including clarithromycin, against Mycobacterium fortuitum, Mycobacterium chelonae, and $M$ chelonae-like organisms. Antimicrob Agents Chemother 1992; 36: 180-4. 